romiting or not, a more doubtful prognosis should be generally given than is usually the case in what is called simple indigestion. Regarding the mode of distingnish. ing cases of perforation of the stomach from natural causes, from those cases which result from corrosive poisons, the author conceived that no appearance observed in the organ should lead to the assumption of poisoning, unless supported by collateral evidence, and the actual detection of the poison by chemical tests. Regarding the treatment of cases of perforation of the stomach, he thought, as the symptoms were doubtful when there was a suspicion of its presence, it was better to keep the patient. quiet in uind and body, and employ local depletion, blistering, and tartar emetic ointment, and not resort to that stimulating plan of treatment, which is too generally employed in those cases which are erronevusly classed under the name of indigestion.

After some observations by Dr. J. Johnson, Dr. Wilkes, Dr. Chowne, and Mr. Brumsgill, the Society adjourned.

\section{ROYAL MEDICAL AND CHIRUR- GICAL SOCIETY.}

Tuesday, March 27 th, 1838.

\section{Dr. Bright, President.}

RESULTS OF POISONING BY SULPHURIC ACID.

\section{By John Wilsun, M.D., Physician to the Middlesex Hospital.}

THe object of the author in this paper, was to describe the condition of the cesophagus in a patient who died 45 weeks after having swallowed a considerable quantity of sulphuric acid. The history of this case had been previously detailed in a paper read at the College of Physicians in $\mathbf{J}$ nly, 1834 , the patient being then alive, at which time a cylindrical tube, eight or nine inches in length, which had been ejected by a vio. lent fit of coughing, was laid on the table. At that time the patient had survived the injury six months, and was soon afterwards discharged from the hospital, in a great measure recovered. She was admitted, however, in the following September, much reduced, and, after very great suffering, died on the 17th of November. On examination post mortem, the lower two-thirds of the oesophagus were thickened and narrowed, and very rascular, and softened internally; the upper third of the tube shone like an old cicatrix. In the stomach opposite to the spleen was an opening of the size of a half-crown, with softened edges; and the abdomen contained a quantity of darkcoloured fluid, but no signs of inflammation. Preparations of the ejected tubular membrane of the osophagus were exhibited to the Society. A coloured model was also exhibited to the meeting of the stomach of another patient, who had died 22 hours after swallowing two or three ounces of sul. phuric acid, which had remained in the stomach a quarter of an hour. The lining of the mouth, pharynx, and osophagus in the latter case was of a silvery-grey speckled appearance, like a snake's skin, and the lining membrane of the stomach was coated with a black pitchlike substance, which did not easily wash off, but which, when scraped off, left the membrane entire.

\section{A paper was also read on the}

\section{USE OF ARSENIC IN SOIIE DISORDERS OF THE UTER US.}

\section{By Henry Hunt, Esq. of Dintmouth, com*} municated by Mr. PERRY.

The author was first led to observe the effects of arsenic on the uterus in a case of carcinoma of that organ, in which it relieved the sufferings of the patient in a remarkable degree, and in exact proportion to the increase of its poisonous effects upon the system. This fact, added to the circumstance of the genital organs being sometimes observed to be inflamed where arsenic has been taken as a poison, induced the author to hope that it might be found to be serviceable in some disorders of these parts, an opinion in which he was encouraged by the experience of $\mathrm{Dr}$. Locock, in a case in which that mineral had been exhibited by him for the cule of a disorder of the nose, he not being aware at that time that the patient was also affected with menorrhagia. The author relates six cases of menorrhagia, in which the patients had taken arsenic with very marked benefit. In these instances there was no organic disease of the uterus; but the excessive flow of the menses ap. peared to be the consequence of exhaustion, originating, however, in several individuals from different causes. The success attending the use of this medicine in menorrhagia induced the author to try it in some other disorders of the uterus, and some favourable cases of its agency are annexed. Some of the most favourable of these are a case of irritable uterus, and one of nemralgia, occurring regularly about the menstrual period, both of which were entirely relieved. The paper concludes with some observa. tions on the effects of arsenic on the genital organs when given in poisonous doses, from which the anthor infers, that its agency de. pends upon its action on the mucous mem. brane as a stimulant.

Dr. Locock said that the case alluded to in the paper as having been treated by him, was the first in which he had noticed the effect of arsenic in arresting menorrhagia. Since the period at which this case occurred, he had seen a great number of instancès 
in which the same remedy was equally successful. Arsenic was most efficient in cases of atonic menorrhagia, but he had employed it with much benefit in cases of the acute form of the affection, after depletion had been resorted to. Respecting the use of arsenic in cases of cancer of the uterus, he had had a case some years since in which the pain was so excruciating as almost to set the influence of narcotics at defiance. As much as 24 grains of the acetate of morphia, in 24 hours, gave little relief. In a consultation with Sir B. Brodie, the use of arsenic was suggested, Sir A. Cooper having found it remarkably efficacious in a case of cancer of the womb. Small doses of the liquor arsenicalis, given repeatedly in the day, but never collectively, amounting to more than ten drops in the 24 hours, afforded the patient more relief than the dose of acetate of morphia just mentioned.

Dr. Merriman could have wished that the cases of menorrhagia, related by $\mathrm{Mr}$. Hust, had been given more in detail. In only two instances had the author made an examination per vaginam, in consequence of which we were left in ignorance of the state of the uterus in the other cases. Menorrhagia might be the result of causes in no way implicating disease of the uterus itself; and he (Dr. M.) thought the nuthor had not clearly made out, in all his eases, the proposition he wished to establish, that arsenic had a specific and local effect on the uterus. Regarding cances of the uterus, we found, occrsionally, that a remedy which was remarkably benenicial in one or two cases of the disease, failed when resorted to in other instances. About the time Mr. Carmichael published some observations on the effects of the preparations of steel in cancerous affections, he (Dr. M.) had under his care a severe case of cancer of the uterns. He gave the carbonate of iron internally, with the effect of considerably increasing the sufferings of the patient. An injection of a solution of sulphate of iron had, however, a remarkably soothing and beneficial effect. He had not found such benefit from the remedy in other cases of the disease, though occasionally it had afforded some relief.

Dr. Leovard Stewart believed that the curative effect of the arsenic in Mr. Hunt's cases depended on its specific and local action on the uterus. Many cases were on recold which proved that arsenic acted on the genital organs specifically.

Dr. Locock considered that in many cases the arsenic acted merely as a tonic, but he believed mcre as a local than a general one. He was quite aware that many cases of me. norrhagia depended on causes which did not in any way implicate the uterus. He had seen many cases of menorrhagia from local debility, as after frequent miscarriages, or frequeut parturitions. In this kind of cases the ase of the arsenic was generally most successful. The cases of menorrhagia related by Mr. Hunt were of the atonic kind. In the other cases related by that gentleman the arsenic was employed to relieve the pain which followed inflam. mation of the uterus. It was not generally necessary in cases of menorrhagia in young women to examine the uterus. He (Dr. L.) did not understand the nature of Dr. Merri. man's objections to Mr. Hunt's cases. Mr. Hunt was a sound practitioner, and wonld not employ a remedy like arsenic withont a full inquiry into the history of the case. $\mathrm{He}$ (Dr. L.) had employed arsenic in small doses, in a case of dysmenorrhoea occurring in a hysterical patient. Both the hysteria and painful meastruation were materially relieved. In that case he believed the arse. nic acted on the uterus itself.

Dr. Merriman did not deny that the arsenic in Mr. Hunt's cases had produced great benefit; but he thought no evidence had been adduced to show that the aterus itselí in these cases was affected, to support Mr. Hunt's proposition, that arsenic acted locally and specifically on the womb in the process of cure.

Dr. Burne said, that disordered function of the uterus was often the result of dis. order of the functions in general; let these functions be restored, and the uterus generally would be set right. All the viscera of the pelvis were affected by sympathy with one another; thus we had dysuria in stricture of the rectum, \&c. There were cases, however, in which the function of the uterus was not properly performed, when the other functions of the body were set right; and he thought these were cases in which medicines having a special and direct action on the utorus were most successful. $\mathrm{He}$ had employed ergot of rye in very many cases of menorrhagia with success, and also in those cases of constant discharge of blood from the uterus after abortion. The ergot of rye, either in decoction, infusion, or powder, he had found of great benefit. In cases of painful menstruation, he had found quarter of a grain doses of extract of belladonna of great service, and of more effect in relieving the pain than opium.

ACCOUNT OF A CASE IN WHICE THE ENTIRE LOWER JAW WAS REMOVED ON ACCOUNT OP DISEASE.

By JoHn G. PERPY, Esq., Surgeon of the Foundling Hospital.

The case here related oncurred in the St. Marylebone Infirmary, during the last year, in a young woman of a scrofulous habit, aged 20 years. According to the history given by the patient of the progress of the disease, as well as from the anomalous position of some of the teeth, it appeared pro* 